women. Anaesthesia 1998; 53: 302-5.

4 Suzuki S, Masamune T, Nonaka A, Kumazawa T. Pretreatment with ketamine reduces incidence and severity of pain on propofol injection (Japanese). Masui 2002; 51: 140-3.

5 Hirota K, Lambert DG. ketamine: its mechanism(s) of action and unusual clinical uses. Br J Anaesth 1996; 77: $441-4$.

\section{Continuous extrapleural infusion of ropivacaine in children: is it safe?}

To the Editor:

In contrast to bupivacaine, ropivacaine has not yet been shown to be suitable in the clinical context of continuous intercostal nerve blockade using an extrapleural catheter in children and young infants. ${ }^{1,2}$ After approval of the hospital's Ethical Committee and obtaining parental consent, the pharmacokinetics of an extrapleural bolus of $0.5 \mathrm{~mL} \cdot \mathrm{kg}^{-1}$ ropivacaine $0.2 \%$ followed by a continuous extrapleural infusion at two different rates $\left(0.2 \mathrm{~mL} \cdot \mathrm{kg}^{-1} \cdot \mathrm{hr}^{-1}\right.$ and 0.3 $\mathrm{mL} \cdot \mathrm{kg}^{-1} \cdot \mathrm{hr}^{-1}$, resp.) for $48 \mathrm{hr}$ were evaluated in two children undergoing cardiac surgery via a lateral thoracotomy (patient 1: male, four years old; patient 2: female, six years old). Anesthesia was performed according to our standard protocol and at the end of the operation an extrapleural catheter (20-gauge, multi-orifice, SIMS Portex Ltd., Hythe, UK) was placed as described earlier. ${ }^{3}$ The bolus of ropivacaine $0.2 \%$ was administered when the patients recovered from anesthesia (adequate reactions to verbal command) and the infusion was maintained for $48 \mathrm{hr}$. Total plasma concentrations of ropivacaine and plasma concentration of $\alpha_{1}$-acid glycoprotein were assessed at the hours $\mathrm{t}=1 / 6,1 / 3,0.5,1,3,6,18,30,48,50$, 52 and 54 . Total ropivacaine plasma concentration showed a first peak $30 \mathrm{~min}$ after the initial bolus. Its highest value was measured at the end of the continuous infusion (Figure) and exceeded the limit of 2.2 $\mathrm{mg} \cdot \mathrm{L}^{-1}$ that is accepted to be safe in terms of toxicity as described by Knudsen et al. ${ }^{4}$ The measured concentrations of $\alpha_{1}$-acid glycoprotein remained within the normal range. The capacity of $\alpha_{1}$-acid glycoprotein to buffer the free fraction of ropivacaine which, mainly, is responsible for toxic reactions in the context of a continuous infusion of local anesthetics was, therefore, not increasing. Thus, we may not assume a subsequent decrease in the unbound fraction of ropivacaine. Clinically, no pathological findings in terms of toxicity were found.

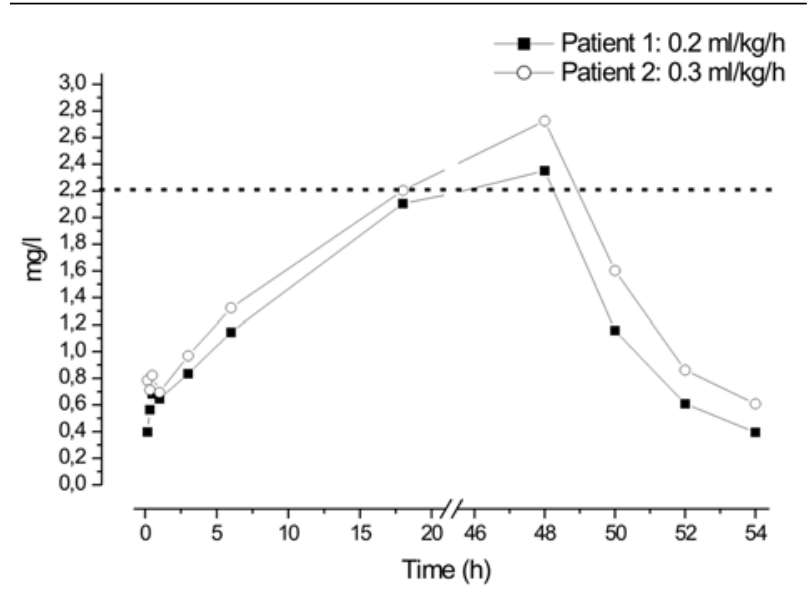

FIGURE Evolution of venous total ropivacaine concentrations. Hours $=$ time in hours after administration of the bolus of ropivacaine. The continuous extrapleural infusion of ropivacaine $0.2 \%$ was stopped at $48 \mathrm{hr}$.

Our preliminary results suggest that intercostal nerve block with an initial bolus of $0.5 \mathrm{~mL} \cdot \mathrm{kg}^{-1}$, followed by a continuous infusion through an extrapleural catheter of $2 \mathrm{mg} \cdot \mathrm{mL}^{-1}$ ropivacaine at $0.2 \mathrm{~mL} \cdot \mathrm{hr}^{-1}$ and 0.3 $\mathrm{mL} \cdot \mathrm{hr}^{-1}$ over $48 \mathrm{hr}$ is at the edge of being considered a safe technique for analgesia after lateral thoracotomy. More investigations - also in terms of pharmacodynamics - are needed to determine the optimal rate and concentration of ropivacaine administered through an extrapleural catheter in children.

Konrad Maurer MD

Katharina M. Rentsch PhD

Alexander Dullenkopf MD

René Prêtre MD

Edith R. Schmid MD

Zurich, Switzerland

Support was provided solely from departmental sources.

\section{References}

1 Downs CS, Cooper MG. Continuous extrapleural intercostal nerve block for post thoracotomy analgesia in children. Anaesth Intensive Care 1997; 25: 390-7.

2 Karmakar MK, Booker PD, Franks R, Pozzi M. Continuous extrapleural paravertebral infusion of bupivacaine for post-thoracotomy analgesia in young infants. Br J Anaesth 1996; 76: 811-5.

3 Sabanathan S, Eng J, Mearns AJ. Alterations in respiratory mechanics following thoracotomy. J R Coll Surg Edinb 1990; 35: 144-50. 
4 Knudsen K, Beckman Suurkula M, Blomberg S, Sjovall $J$, Edvardsson N. Central nervous and cardiovascular effects of i.v. infusions of ropivacaine, bupivacaine and placebo in volunteers. Br J Anaesth 1997; 78: 507-14.

\section{Epidural blood patch in a Jehovah's Witness patient with post-dural punc- ture cephalgia}

To the Editor:

We report a case of epidural blood patch in a Jehovah's Witness (JW) parturient by using a continuous circuit technique. ${ }^{1}$

A young healthy primigravida was scheduled for an elective Cesarean delivery under epidural anesthesia. Accidental dural puncture occurred and the catheter was inserted into the subarachnoid space. $12.5 \mathrm{mg}$ of $0.5 \%$ bupivacaine and $25 \mu \mathrm{g}$ of fentanyl were injected and the Cesarean section was completed uneventfully under a spinal anesthetic.

The subarachnoid catheter was left in place and was removed on postoperative day $(\mathrm{POD})^{1}$. Subsequently she developed a postural, occipital headache consistent with post-dural puncture headache. Initially, hydration, analgesics and iv caffeine were tried, but failed to achieve relief. The possibility of a blood patch was discussed on POD 2, but the patient refused this treatment option and opted for epidural saline. On POD 3, the patient's headache was severe and prevented discharge from the hospital. She accepted the blood patch with the condition that the blood used

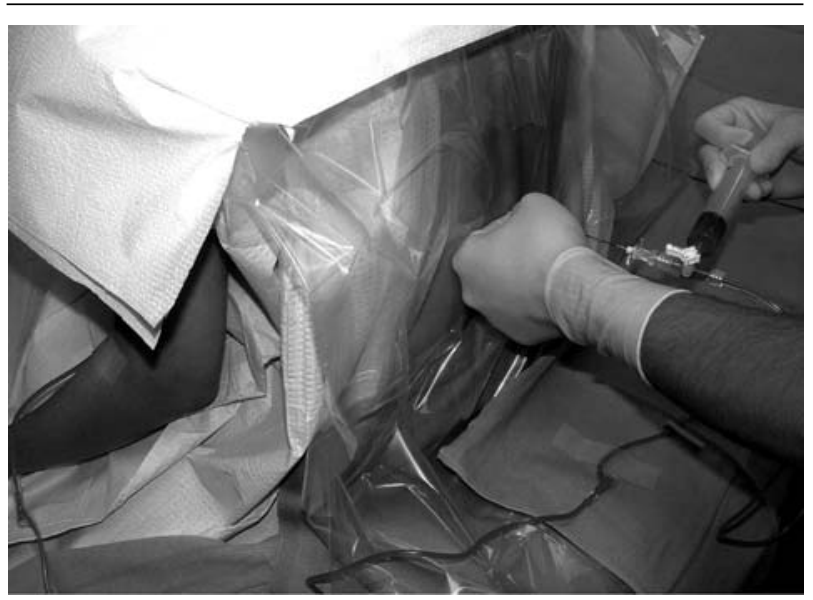

FIGURE Continuous system for obtaining autologous blood and injecting into the epidural space for a blood patch under sterile conditions. remain in a continuous circuit. Utilizing this principle, a continuous circuit was established (Figure). After placement of an 18-gauge Tuohy needle in the L2-L3 epidural space, a four-way stopcock was connected to the needle along with a $20-\mathrm{mL}$ syringe. Using an aseptic technique, an 18 -gauge iv catheter was placed in the left antecubital fossa and connected to a sterile $i v$ extension tubing. Subsequently a 36 -inch pressure tubing with male luer locks on both ends was connected to the $i v$ extension tubing. The other end was connected to the four-way stopcock completing the circuit. Twenty millilitres of blood were aspirated and injected into the epidural space, providing complete relief within two hours. The patient was discharged home on POD 4 and remained free of complications.

Management of an epidural blood patch can be a challenge in the JW patient. The JW belief is that "a Christian ought to focus, not primarily on whether a brief interruption in flow might occur, but on whether he conscientiously believed that the diverted blood would still be part of his circulatory system". ${ }^{2}$ Our montage is acceptable since the JW patient believes that, despite the stopcock, the tubing acts as an external conduit for blood to flow, even though the flow may be interrupted briefly. We believe that this method is more user friendly than other methods described ${ }^{3-5}$ and will be accepted by most JW parturients.

Narasimhan Jagannathan MD

John E. Tetzlaff MD

Cleveland, Ohio

\section{References}

1 Muramoto $O$. Recent developments in medical care of Jehovah's Witnesses. West J Med 1999; 170: 297-301.

2 Watch Tower Bible and Tract Society. Questions from readers. The Watchtower 1989; March 1: 30-1.

3 Brimbacombe J, Clarke G, Craig L. Epidural blood patch in the Jehovah's Witness (Letter). Anaesth Intensive Care 1994; 22: 319.

4 Bearb ME, Pennant JH. Epidural blood patch in a Jehovah's Witness (Letter). Anesth Analg 1987; 66: 1052.

5 Kanumilli V, Kaza R, Johnson C, Nowacki C. Epidural blood patch for Jehovah's Witness patient (Letter). Anesth Analg 1993; 77: 872-3. 